\title{
The Monitoring and Feedback for the Construction Quality of the Mass Concrete Based on the Distributed Optical-Fiber Temperature Measurement System
}

\author{
Feng $\operatorname{Jin}^{*}, 1,2$ and Yihong Zhou ${ }^{2}$ \\ ${ }^{I}$ State Key Laboratory of Water Resources and Hydropower Engineering Science, Wuhan University, Wuhan, 430072, \\ P.R. China \\ ${ }^{2}$ College of Hydraulic \& Environmental Engineering, China Three Gorges University, Yichang 443002, P.R. China
}

\begin{abstract}
Temperature control is a key factor which affects the construction quality of the mass concrete, which is also an important measure to prevent crack propagation. Lots of engineering practices show that most of temperature cracks come out in the form of the surface crack during the construction of the concrete dam. In addition, deep cracks and transverse cracks are usually developed by surface cracks. Strengthening conversation and surface insulation are one of the main methods to prevent surface cracks. In this paper, Xiluodu hydropower dam is taken as the engineering background, and an insulation monitoring experiment under the winter low-temperature condition was carried out on the fresh concrete layer during the construction period using the distributed fiber optic temperature monitoring system. The inversion of the equivalent heat coefficient for the fresh concrete layer with the covering of the polyethylene membrane insulation materials was conducted, besides the monitoring results and the feedback analysis of the conservation status was obtained based on the test data. The above procedure provides a basis for evaluating the quality of construction and the dynamic adjustment of the construction programs.
\end{abstract}

Keywords: Mass concrete, distributed fiber optic monitoring, temperature control, construction quality.

\section{INTRODUCTION}

The alternative bay construction technology is usually adopted for mass concrete with block columnar pouring [1], and will form different pouring progress from low casting warehouse to high casting warehouse as shown in Fig. (1). High pouring warehouse has five surface exposed to the atmosphere, as well as low casting warehouse only has three. Due to the increasing of the free face of the pouring warehouse, the heat exchange area between the pouring block and the surroundings will be significantly increased correspondingly. Any surface exposed to the atmosphere will generate cracks because of the large temperature gradient. Therefore, it is urgently needed to adopt conservation and surface insulation technology to the pouring concrete warehouse [2].

Different conservation and insulation measures are usually adopted in order to reduce the temperature difference between inside and outside concrete in different parts of the surface of the pouring warehouse. The specific operation is to do as follows: the upstream face is externally bonded with the polystyrene foam board for the purpose of heat preservation and dismantled before impoundment, while the downstream face is externally bonded with the same material for permanent insulation and maintained regularly during the

\footnotetext{
*Address correspondence to this author at the State Key Laboratory of Water Resources and Hydropower Engineering Science, Wuhan University, Wuhan, 430072, P.R. China; Tel: 15501162945; E-mail: jf@ whu.edu.cn.
}

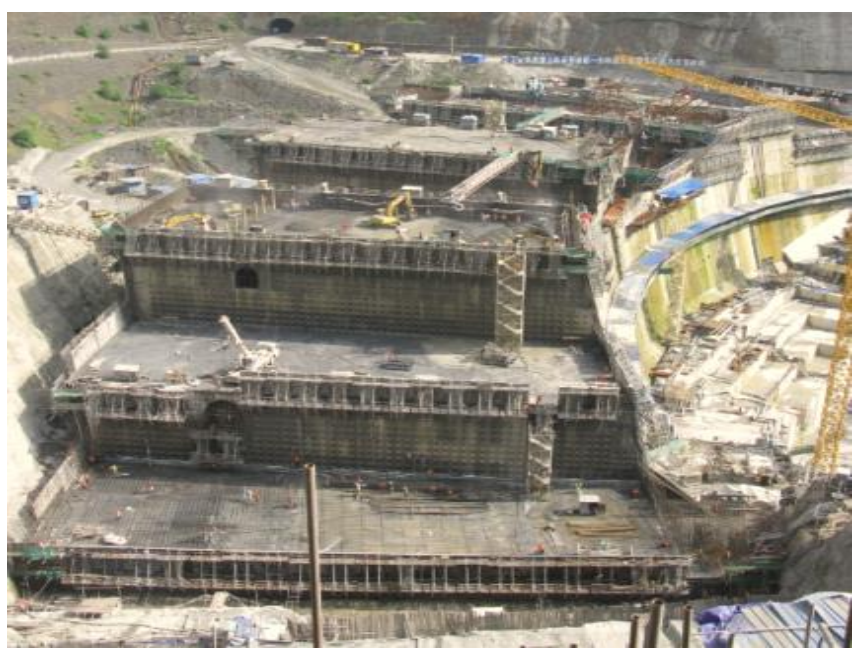

Fig. (1). Alternative bay construction technology in the construction onsite.

whole service time. In addition, the transverse joint surface is also externally bonded with the polystyrene foam board in order to keeping the temperature constant and removed till the pouring of the dam concrete of the other side of the transverse joint surface. Depending on different seasons and different temperature conditions, the water conservation and polyethylene membrane covering are applied for heat preservation on the fresh concrete layer with wet curing [1]. 
The temperature control of the fresh concrete layer is a complex multifactorial space-time problem, which is affected by concrete nature, pouring temperature, cooling of the internal pipes, conservation measures and the external environment, besides the cold strike influence on the new pouring outer layer of the low-temperature concrete [3]. Traditional point thermometer can not realize the real-time, and dynamic monitoring on all parts of pouring block, especially the temperature change process on the concrete surface. The dynamic temperature conditions of the fresh concrete level can be acquired through the inversion of concrete thermal parameters using the continuously monitored value by the embedded distributed optical-fiber, which possesses the advantage of high sensitivity, highprecision, and high degree of automation [4-6]. The application of the temperature measurement system on the monitoring of the concrete temperature based on the distributed optical-fiber technology is an important means for the dynamic monitoring of the concrete pouring quality and conversation quality [6].

\section{PRINCIPLE ON THE CONSERVATION STATUS MONITORING OF THE FRESH CONCRETE LAYER BASED ON DISTRIBUTED OPTICAL-FIBER TECHNOLOGY}

Fig. (2) shows the principle on the conservation status monitoring of the fresh concrete layer based on distributed optical-fiber technology.

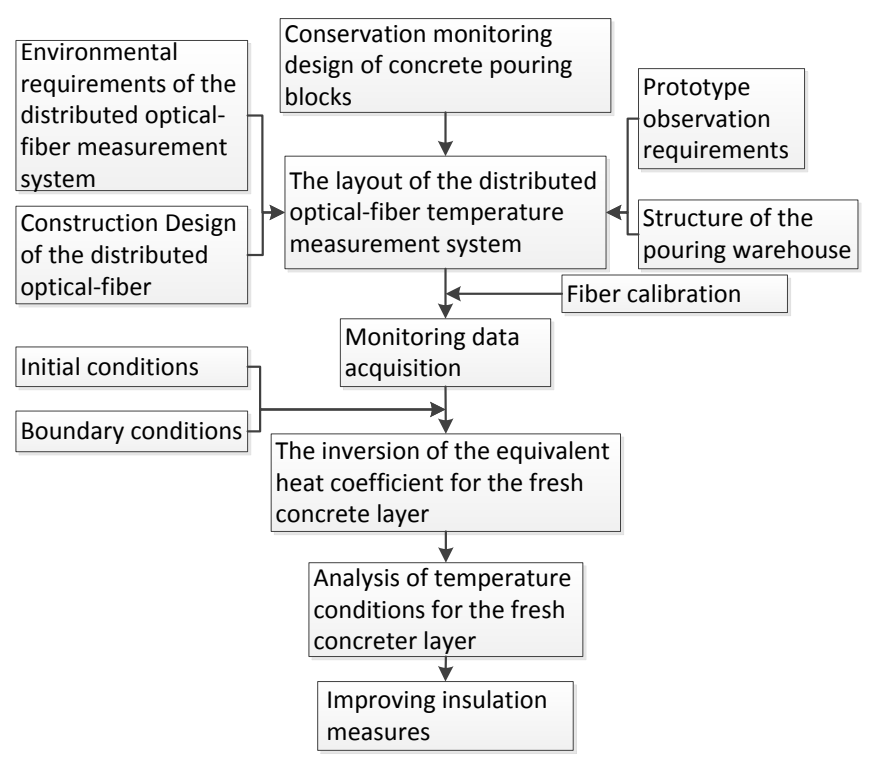

Fig. (2). Schematic of the conservation status monitoring of the fresh concrete layer.

\section{BASIC PRINCIPLES OF THE INVERSION OF THE SURFACE HEAT TRANSFER COEFFICIENT}

3.1 Estimation of the Equivalent Surface Heat Transfer Coefficient Considering Material Thermal Resistance

When the concrete surface covered with insulation, the equivalent surface heat transfer coefficient is still able to calculated according to the third boundary condition with considering the impact of the insulation material. The equivalent surface heat transfer coefficient $\beta$ s is calculated by the following formula 1 , which represents the heat exchange between concrete surface insulation layer and the surrounding [2]:

$$
\beta_{s}=\frac{1}{(1 / \beta)+\Sigma\left(h_{i} / \lambda_{i}\right)}
$$

Where,

$\beta_{s}$---the equivalent surface heat transfer coefficient;

$\beta$---surface heat transfer coefficient of the template or insulation in the atmosphere;

$h_{i}$---insulation thickness of the $i$ th layer;

$\lambda_{i}$---insulation thermal conductivity of the $i$ th layer.

\subsection{Inversion Analysis of the Surface Heat Transfer Coefficient Based on the Real-time Measured Temperature}

As shown in Fig. (3), 3 thermometers a, b, and c embedded in the considered infinite element measure the real-time temperature in a transient, which are denoted as $\mathrm{Ta}, \mathrm{Tb}, \mathrm{Tc}$, and temperature on the concrete surface and in the atmospheric are referred to as $\mathrm{Ts}$ and $\mathrm{Ta} 0$, respectively. Assuming that the coordinate origin is set at the location of a thermometer, and then the temperature at $\mathrm{x}$ point and at the surface of the concrete are expressed as $\mathrm{T}=\mathrm{T}(\mathrm{x})$ and $\mathrm{Ts}=\mathrm{T}$ (-a) respectively [1]. The surface heat transfer coefficient can be obtained by using quadratic interpolation method.

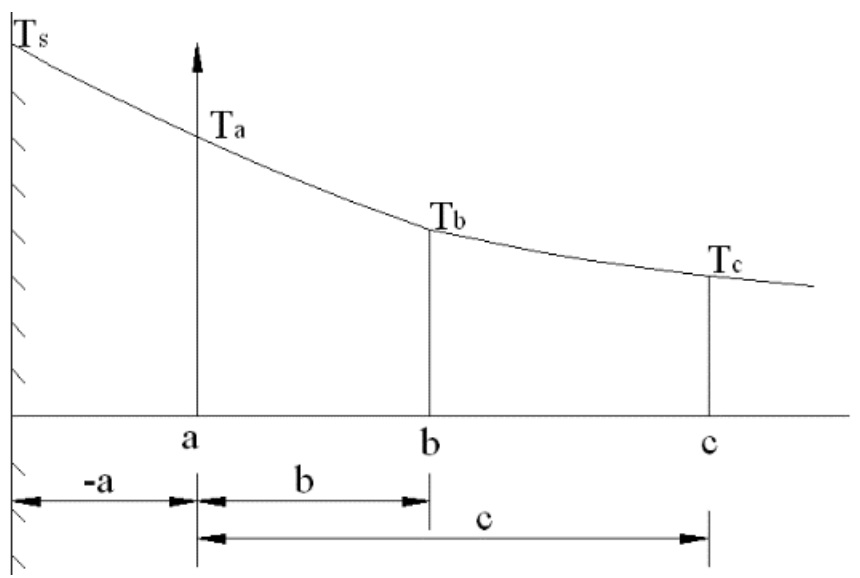

Fig. (3). Schematic of the thermometer arrangement on the concrete surface.

The temperature near the surface is expressed as follows:

$$
\begin{aligned}
& T=T(x)=k_{1}+k_{2} x+k_{3} x^{2} \\
& \left\{\begin{array}{l}
x=0, T=T_{a}=k_{1} \\
x=b, T=T_{b}=k_{1}+k_{2} b+k_{3} b^{2} \\
x=c, T=T_{c}=k_{1}+k_{2} c+k_{3} c^{2}
\end{array}\right.
\end{aligned}
$$

And then the temperature on the surface of the concrete $x=-a$ is expressed as follows: 


$$
\left\{\begin{array}{l}
T_{s}=k_{1}-k_{2} a+k_{2} a^{2} \\
\left(\frac{\partial T}{\partial x}\right)_{s}=k_{2}-2 a k_{3}
\end{array}\right.
$$

By the formula that,

$\lambda \frac{\partial T}{\partial x}=\beta\left(T_{s}-T_{a 0}\right)$

The calculation formula of the surface heat transfer coefficient can be derived as follows:

$$
\beta=\frac{\lambda\left(\frac{\partial T}{\partial x}\right)_{s}}{T_{s}-T_{a 0}}
$$

Where,

$\beta$---the surface heat transfer coefficient;

$T_{a 0^{--}}$-the ambient temperature;

$T_{s}$---the temperature of the concrete surface;

$\lambda$---thermal conductivity of the concrete.

By applying the Formula (6), the surface heat transfer coefficient under the bare condition not only can be obtained, but also the equivalent surface heat transfer coefficient, which represents insulation effect of the surface insulation materials [1].

In this paper, a typical pouring warehouse was chosen to be embedded with the distributed optical-fiber at different depth from the surface. As the temperature of the pouring warehouse real-time monitored online, the equivalent surface heat transfer coefficient was inversed by the monitoring value.

\section{ENGINEERING APPLICATION}

Xiluodu dam is an ultra-high double curvature arch dam, with the maximum height of $285.5 \mathrm{~m}$, which is divided into 31 pouring sections. For the purpose of preventing cracks by temperature control measures, conventional thermometers were embedded in the pouring concrete warehouse, while the $5 \#, 15 \#, 16 \#$,and the $23 \#$ pouring concrete warehouse was embedded with distributed optical-fiber for temperature monitoring. According to the technical requirements of construction, fresh concrete layer was covered with $5 \mathrm{~cm}$ polyethylene membrane for insulation, whose surface heat transfer coefficient must be satisfied as $8.1147 \mathrm{~kJ} /\left(\mathrm{m}^{2} \cdot \mathrm{h}^{\circ} \cdot{ }^{\circ} \mathrm{C}\right)$.

\subsection{Experimental Program Design}

5\#-025 was adopted as a typical pouring warehouse on the steep slopes, whose concrete grade is $C_{180} 35$. The pouring warehouse, with the thickness of $3 \mathrm{~m}$, is divided into 6 pouring layers. A layer of pipes were arranged on the top surface of the pouring layer 1 and pouring layer 4 , whose spacing is $1.5 \mathrm{~m} \times 1.0 \mathrm{~m}$. The arrangement of the optical-fiber was indicated in Fig. (4). A layer of fiber should be arranged at the position of $0.2 \mathrm{~m}$ below the top surface of pouring layer 3 , while at the position of $0.08 \mathrm{~m}, 0.2 \mathrm{~m}, 0.4 \mathrm{~m}$ below the top surface of pouring layer 6.Among this, 10 monitoring points of each optical-fiber layer were chosen to monitor, depicting average temperature as the real-time temperature for the relevant parts. Take the optical-fiber temperature measurements at the position of $0.08 \mathrm{~m}$ below the top surface of pouring layer 6 as the average temperature of the fresh concrete layer. The optical-fiber located at $0.08 \mathrm{~m}, 0.2 \mathrm{~m}, 0.4 \mathrm{~m}$ were fixed by steel, as shown in Fig. (5). The automatic data collection period of the distributed optical-fiber temperature measurement system (DTS) is 1 hour. The mixture ratio of concrete in 5\#-025 pouring house and the typical moment are respectively shown in Table $\mathbf{1}$ and Table $\mathbf{2}$.

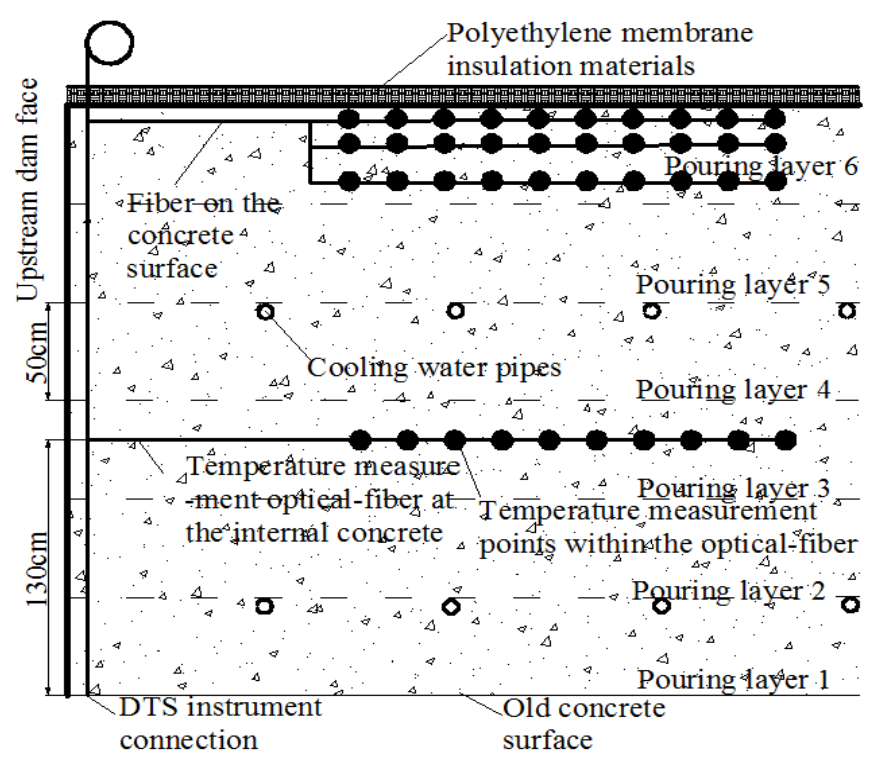

Fig. (4). Schematic of the distributed optical fiber layout.

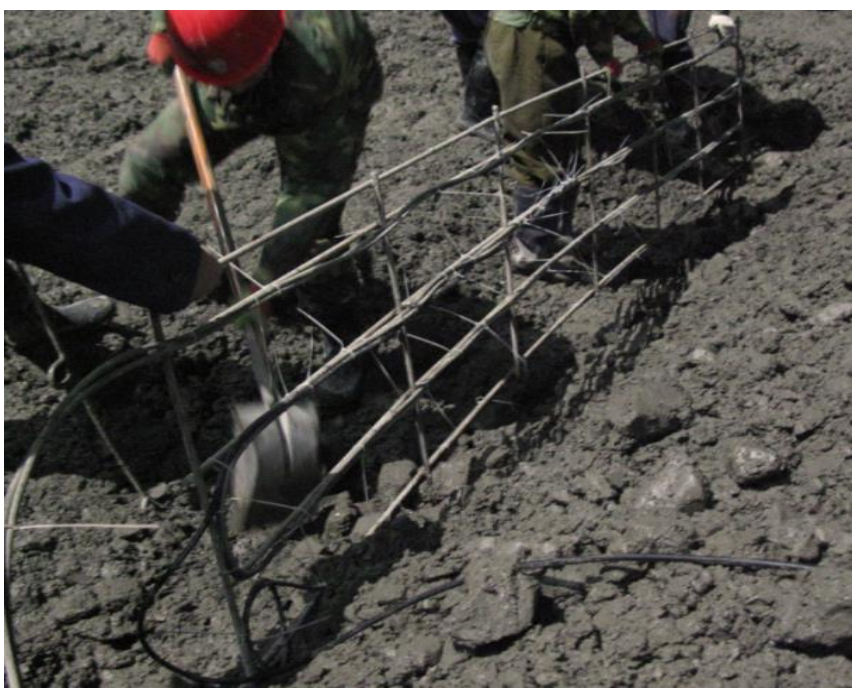

Fig. (5). On-site schematic of optical fiber layout.

\subsection{Optical Fiber Temperature Measurement Results of the Analysis}

The fresh concrete pouring warehouse completed all the construction procedure before concrete pouring on December 23, 2011, and which was covered for heat preservation on December 28. The construction datum time 
Table 1. Proportion of the concrete material.

\begin{tabular}{|c|c|c|c|c|c|c|c|}
\hline $\begin{array}{c}\text { Strength } \\
\text { grade }\end{array}$ & Grading & $\begin{array}{c}\text { Water- } \\
\text { cement ratio }\end{array}$ & $\begin{array}{c}\text { The amount } \\
\text { of cement } \\
\left(\mathrm{kg} / \mathrm{m}^{3}\right)\end{array}$ & $\begin{array}{c}\text { The amount } \\
\text { of water } \\
\left(\mathrm{kg} / \mathrm{m}^{3}\right)\end{array}$ & $\begin{array}{c}\text { Amount of } \\
\text { fly ash } \\
\left(\mathrm{kg} / \mathrm{m}^{3}\right)\end{array}$ & $\begin{array}{c}\text { The total } \\
\text { amount of } \\
\text { gelled } \\
\text { material } \\
\left(\mathrm{kg} / \mathrm{m}^{3}\right)\end{array}$ & $\begin{array}{c}\text { Dosage of fly } \\
\text { ash (\%) }\end{array}$ \\
\hline \hline $\mathrm{C}_{180} 35$ & $\mathrm{IV}$ & 0.45 & 130 & 90 & 70 & 200 & 35 \\
\hline
\end{tabular}

Table 2. No. 5 dam no.025 storehouse's baseline timetable.

\begin{tabular}{|c|c|c|}
\hline Time & Event & Remark \\
\hline \hline 2011-12-23 21:14 & 5\#-025 construction procedure completed before concrete pouring & - \\
\hline 2011-12-24 22:00 & Laying the 3 layer temperature measuring optical fiber along the river & Monitor the internal temperature of pouring warehouse \\
\hline $2011-12-27$ & 5\#-025 clearance & Layer conservation with water \\
\hline 2011-12-28 08:00 & Covering heat preservation on the top & The thickness of the heat preservation is 5 $\mathrm{cm}$ \\
\hline 2012-1-5 20:00 & Uncovered the heat preservation & 5\#-026 spare warehouse \\
\hline 2012-1-6 17:10 & 5\#-026 construction procedure completed before concrete pouring & 2012-1-7 22:30 concrete pouring \\
\hline
\end{tabular}

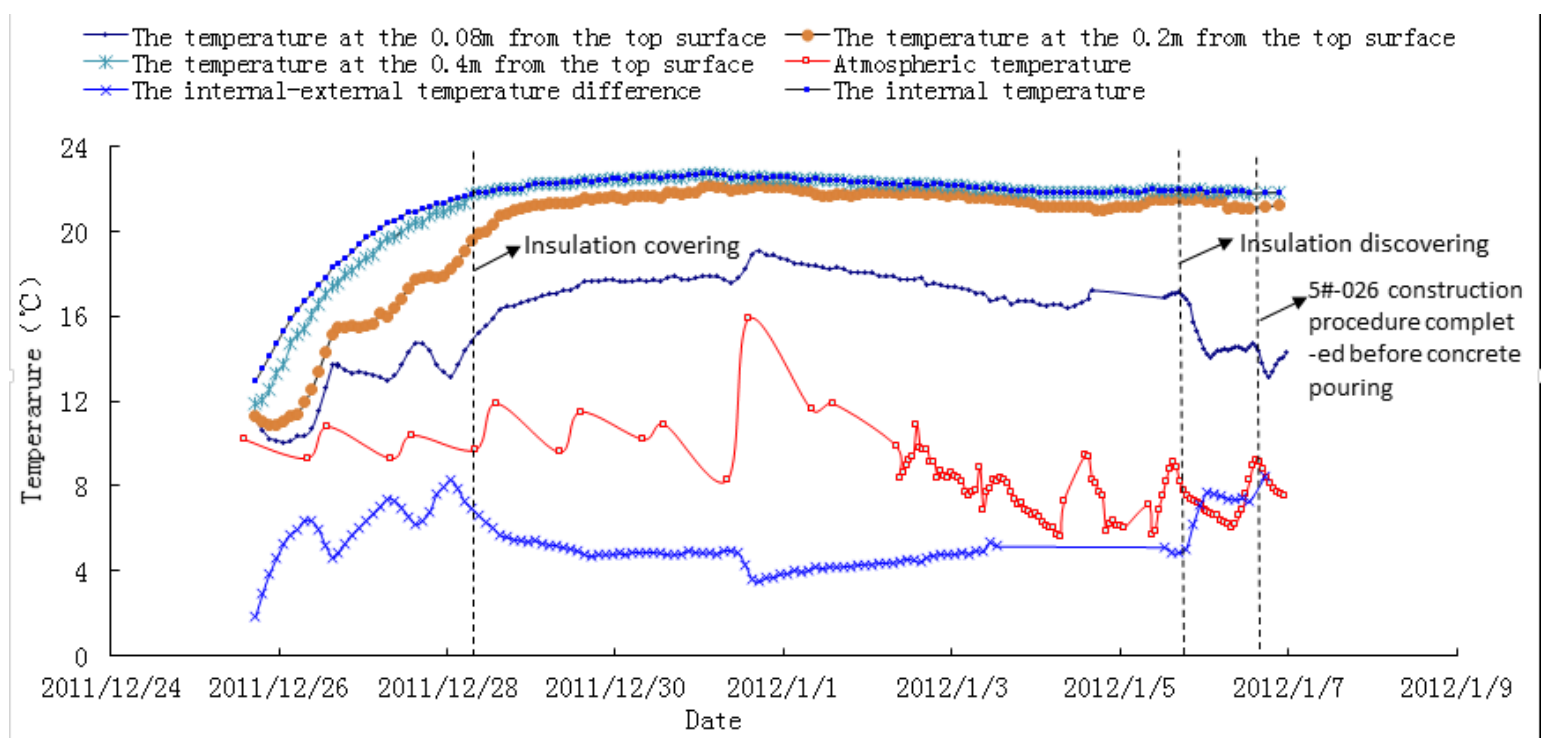

Tips: Internal-external temperature difference in the figure is referred as that from the inside of the pouring concrete warehouse to the position of $8 \mathrm{~cm}$ below the top surface.

Fig. (6). The duration curve of the average temperature.

of the pouring warehouse is shown in Table 2 , the fiber optic temperature monitoring process curve is shown in Fig. (6).

The average temperature duration curve of the fresh concrete layer comprehensively reflect the influence of the temperature and insulation measures, besides the cold strike impact of the post-pouring concrete at the upper layer.

There are some descriptions of the average temperature duration curve of the fresh concrete layer:

(1) The fresh concrete layer of the $5 \# 025$ pouring warehouse was wet cured after pouring. Suffering from the effect of the ambient temperature change amplitude and internal hydration heat rising, layer temperature rose gradually, whose change amplitude was consistent with the atmospheric temperature. The maximum temperature difference between the inside and the outside concrete surface can reach up to $7.2^{\circ} \mathrm{C}$;

(2) After being covered with insulation, the temperature change amplitude of the fresh concrete layer can not be effected significantly by that of the atmospheric temperature, and may have a slight change only when the atmospheric temperature increased rapidly up to more than $4{ }^{\circ} \mathrm{C}$.For example, the atmospheric temperature increased rapidly up to $7.6^{\circ} \mathrm{C}$ from $8: 00$ to $14: 00$ on the December 31, 2011, and the temperature of the fresh concrete layer had a slight change of $0.66{ }^{\circ} \mathrm{C}$. The 
temperature difference between the inside and the outside concrete surface was controlled at $4^{\circ} \mathrm{C}$, inferring that the polyethylene insulation materials were provided with obvious insulation effect;

(3) The temperature on the fresh concrete surface decreased rapidly following the heat preservation had discovered at 20:00 on January 5th 2012 , with the cooling rate reached $2.89{ }^{\circ} \mathrm{C} / \mathrm{d}$, which leaded to the cold strike impact. Temperature difference between inside and outside of the concrete reached $7.68{ }^{\circ} \mathrm{C}$, forming a negative temperature gradient below the fresh concrete layer;

(4) The concrete of the upper layer was poured at $12{ }^{\circ} \mathrm{C}$, forming a cold strike impact on the fresh concrete layer once again, with the cooling rate of $1.75{ }^{\circ} \mathrm{C} / \mathrm{d}$ at $17: 10$ on January 6, 2012. At this time the outside temperature was $7.5^{\circ} \mathrm{C}$.

\subsection{Surface Heat Transfer Coefficient Inversion Analysis}

Thermal conductivity of the dam's concrete adopts the design value $\lambda=184.9 \mathrm{~kJ} /\left(\mathrm{m}^{2} \mathrm{~d}{ }^{\circ} \mathrm{C}\right)$, using the daily mean temperature, after layered covering polyethylene coil the test casting warehouse began to heat preservation. At this time select the typical time using the Formula (6) to inversion analysis the heat transfer coefficient of concrete surface. The typical time of inversion analysis is December 28, 2011 to January 5, 2012.During covering the insulation, Three fiberoptic temperature measurement value is used corresponding the measuring point corresponding that $0.08 \mathrm{~m}, 0.2 \mathrm{~m}, 0.4 \mathrm{~m}$ below the top surface grey layer 6 , the mean value after inversion of surface exothermic coefficient is $8.1147 \mathrm{~kJ} /\left(\mathrm{m}^{2}\right.$ $\mathrm{d}{ }^{\circ} \mathrm{C}$ ), meet the technical requirements of construction temperature control to of the concrete arch dam which requests.

\section{CONCLUSION}

Distributed optical fiber temperature measurement technology can dynamically reflect the surface temperature situation of the concrete, providing a basis for evaluating the quality of construction and the dynamic adjustment of construction measures.
Based on the temperature data of distributed optical-fiber embedded on top surface of the typical pouring warehouse, the transfer coefficient with covering the heat preservation layer was inversed, and the value of the surface heat transfer coefficient $\beta$ could be obtained as $8.1147 \mathrm{~kJ} /\left(\mathrm{m}^{2} \mathrm{~d}{ }^{\circ} \mathrm{C}\right)$, , which satisfied the construction requirements for temperature control of concrete pouring.

When the temperature is lower than that of the upper fresh concrete layer in cold season, for the purpose of reducing the cold strike impact, the moment that uncovered the heat preservation should be taken as the moment that all construction procedure had completed before the concrete pouring, in other words, the fresh concrete layer should be poured after heat preservation uncovered immediately.

\section{CONFLICT OF INTEREST}

The author confirm that this article content has no conflict of interest.

\section{ACKNOWLEDGEMENTS}

Declared none.

\section{REFERENCES}

[1] B. Zhu, Mass Concrete Temperature Stress and Temperature Control, Beijing, China Electric Power Press, pp.235-238, 2012.

[2] B. Zhu, and C. Zhang, Research on the Structural Safety of High Concrete Arch Dams, Beijing: China Water Power Press, pp. 269272, 2010.

[3] Y. Zhou, J. Zhou, and Y. Huang, Concrete low-temperature placing monitoring experiment and feedback analysis based on distributed optical fiber, Water Power, vol.38, no. 2, pp. 25-27, Jun. 2012.

[4] R. M. Measures, T. Alavie, R. Maakant, and S. Y. Huang, "Bragg grating fiber optic sensing for bridge and other structure," $2^{\text {nd }}$ European Conference on Smart Structures and Materials, Glasgow, Scotland, 1994d, SPIE, pp.162-167, October 12-14,1994.

[5] M. A. fleger, T. Strobl, and J. Dornstadter, "Fibre Optic Temperature Measurements for Dam Monitoring," International Conference on Health Monitoring of Civil Infrastructure Systems, Chongqing University Press, pp.121-128, October 24-26,1994.

[6] D. Cai, Application of Optical Fiber Sensing Technology in Dam Project, Beijing, China Water Power Press, pp.166-168, 2013.

Received: September 17, 2014

Revised: December 17, 2014

Accepted: December 23, 2014

(C) Jin and Zhou; Licensee Bentham Open.

This is an open access article licensed under the terms of the Creative Commons Attribution Non-Commercial License (http://creativecommons.org/licenses/ by-nc/3.0/) which permits unrestricted, non-commercial use, distribution and reproduction in any medium, provided the work is properly cited. 